\title{
Extracción de cloruros de piezas arqueológicas metálicas recuperadas del fondo del mar
}

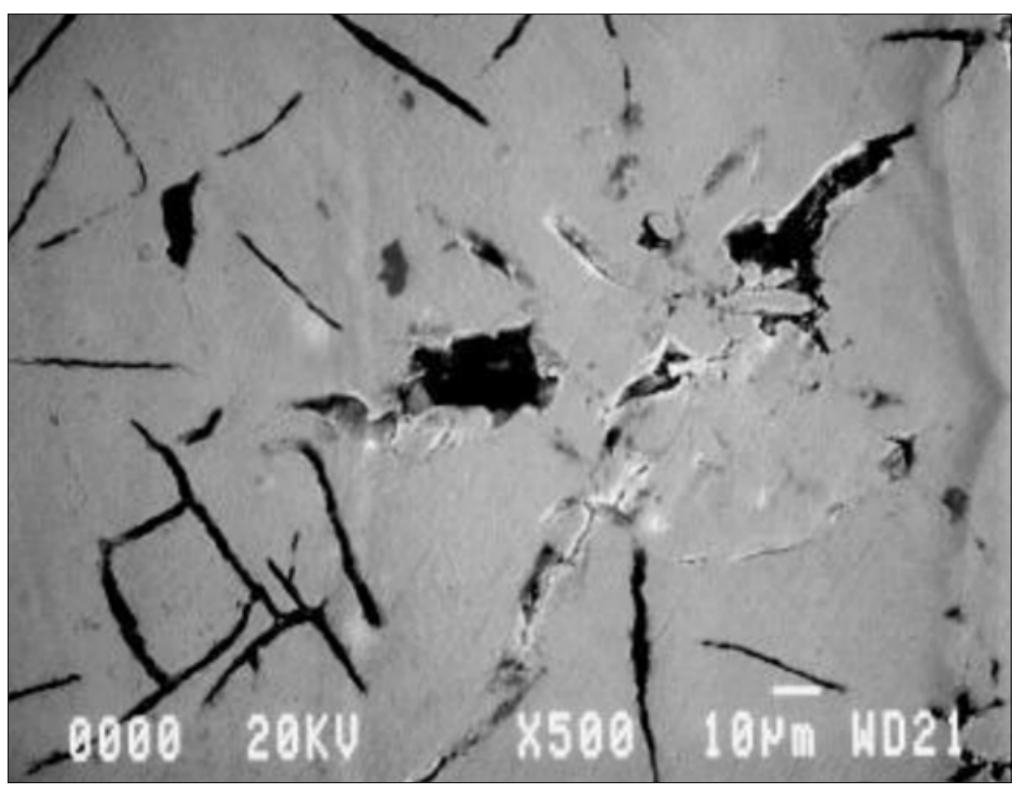

\section{M.L. Almoraima Gil \\ Departamento de Química Física Universidad de Cádiz}

\section{Resumen}

La conservación de las piezas metálicas extraídas de fondos marinos, exige seguir un tratamiento de estabilización para impedir el desarrollo de la corrosión cíclica debida a los cloruros depositados en el metal por el agua del mar, cuando la pieza es extraída y secada, es posible que la corrosión continúe por la presencia de especies cloradas higroscópicas. Conocer los períodos que atraviesa el proceso, permite elegir con mayor eficacia el método para eliminar los cloruros.

\section{Palabras clave}

Eliminación de cloruros / Metales arqueológicos

\section{Introducción}

Los principales factores que determinan la velocidad de la corrosión marina: composición del metal, y del agua, temperatura, crecimiento de concreciones calcáreas, etc., están relacionados entre sí haciendo que el proceso sea muy complejo y los productos formados de naturaleza muy variada.

Cuando un metal se sumerge en agua con un alto contenido en oxígeno, tienen lugar una serie de reacciones en diferentes lugares de la superficie del metal. En las zonas anódicas la oxidación del metal produce iones metálicos con carga positiva y electrones. 


$$
\text { Metal } \rightarrow \text { Metal }^{+}+\mathrm{e}^{-}
$$

Simultáneamente en las zonas catódicas el oxígeno se reduce aceptando electrones y produciendo iones con carga negativa

$$
\mathrm{O}_{2}+2 \mathrm{H}_{2} \mathrm{O}+4 \mathrm{e}^{-} \rightarrow 4 \mathrm{OH}
$$

Para mantener la neutralidad del metal los electrones y los iones tienen que trasladarse de las zonas anódicas a las catódicas. Los electrones se mueven dentro del seno metálico y los iones por difusión en la disolución, los iones que participan en la neutralización no tienen que ser necesariamente los producidos en las reacciones anteriores. En el mar la alta concentración de iones en disolución colabora en el proceso de neutralización, incrementando la velocidad, al facilitar el flujo de las corrientes de corrosión.

Los cloruros en disolución, se incorporan en la primera monocapa de productos de la reacción, sobre la superficie metálica (I). La concentración de cloruros en la capa de corrosión debe ser inferior a 200 ppm, si se sobrepasa esta cifra hay que pensar en contaminación durante la extracción o que la pieza proviene de una zona litoral. Al quedar ocluidos en la red cristalina formada por los productos de corrosión, deben convertirse en cloruros libres y extraerse rápidamente mientras se mantienen condiciones reductoras o por lo menos anaerobias, para prever corrosiones posteriores antes de que sean totalmente eliminados. La elección del tratamiento depende principalmente de la extensión de la corrosión y de la necesidad de preservar los productos de corrosión estables que determinan el estado de la superficie original del objeto, donde generalmente se encuentra la información más valiosa para el arqueólogo.

\section{Periodos del proceso de corrosión del hierro}

Uno de los metales más abundantes en los yacimientos arqueológicos es el hierro que puede clasificarse como hierro fundido cuando contiene un $2 \%$ de carbono o hierro forjado si tiene entre un $2 \%$ y un $6 \%$ de carbono. La naturaleza de los productos de corrosión formados en el proceso de oxidación de piezas de hierro en el fondo del mar depende del tiempo de inmersión de la pieza y de los cambios que se produzcan en el entorno. Según North (2), se pueden establecer cuatro periodos distintos que no tienen que darse necesariamente en todos los casos.

En el período inicial debido a que el hierro no es un material biológicamente tóxico, la pieza se recubre totalmente de una capa de concreción por deposito de material calcáreo, producido por la interacción de los productos de corrosión y los organismos marinos en un proceso conocido como "fouling", que suele durar entre dos y tres años.

Posteriormente en el periodo de concreción-corrosión, dentro del volumen que ocupa el hierro sólido, actúa la corrosión, la reacción anódica oxida el hierro metálico y simultáneamente dentro de la concreción se produce la reacción catódica de reducción del oxígeno del agua.

En el siguiente período, cuando todo el hierro se corroe, se consigue un estado de equilibrio con el medio que conduce para el caso del hierro fundido, a la desaparición total de la pieza metálica original, quedando un espacio vacío dentro de un molde de concreción, o si el hierro era originalmente hierro forjado a la grafitización total de la pieza.

En el período final, al comenzar la excavación, cambia el entorno alterándose la composición de las sustancias producidas por los procesos anteriores. Desde el punto de vista de la conservación, estas sustancias alteradas son más importantes que las producidas originalmente por la corrosión, por tanto las condiciones en las que se lleva a cabo la extracción y traslado de la pieza determinan su posterior estabilización.

\section{Métodos de estracción de cloruros de piezas de hierro}

Se debe eliminar como mínimo un 95\% (3) de los cloruros para estabilizar la pieza. Hasta el momento no se ha encontrado un tratamiento que consiga total efectividad, y además para determinar cuando se debe dar por finalizada la extracción, sería necesario conocer la concentración de cloruros en distintas partes del interior del objeto, dado que la composición, porosidad y estructura del material oxidado no son homogéneas y por tanto el resultado del tratamiento no será uniforme, generalmente se da por terminado el proceso cuando la concentración de cloruros en el baño de decloración es menor que 50 ppm. Los métodos más extensamente utilizados se pueden clasificar en dos grandes grupos:

\section{Lavados intensivos}

Este método consiste en sumergir la pieza en una disolución acuosa de $\mathrm{NaOH}, \mathrm{CO} 3 \mathrm{Na}$ o $\mathrm{CO} 3 \mathrm{HNa}$, y mantener la concentración de cloruros en la disolución por debajo de 100ppm, renovando el baño para favorecer la difusión de los cloruros hacia la disolución. Antes de finalizar hay que extraer los restos de hidróxido o carbonato que contenga la pieza con sucesivos lavados. El proceso es muy lento, se acelera con agitación, puede utilizarse como paso previo al uso de otro tratamiento más eficaz.

\section{Reducción de los productos de corrosión}

Una forma de acelerar la difusión de los cloruros desde el interior de la pieza es aumentar su porosidad, convirtiendo por reducción, los productos de la corrosión en compuestos más densos, esto se puede conseguir utilizando varios métodos.

Reducción con sulfito sódico (Na2SO3) en medio alcalino (4) La pieza se sumerge en una disolución de sulfito sódico en medio básico a $50^{\circ} \mathrm{C}$, controlando la concentración 
de cloruros y renovando la disolución. Consolida el objeto y extrae los cloruros, generalmente se utiliza en piezas de origen terrestre que tienen un contenido en cloruros menor que las marinas.

\section{Corriente de hidrógeno a altas temperaturas (5)}

La pieza a tratar se coloca en un horno con atmósfera de hidrógeno a más de $400^{\circ} \mathrm{C}$, obteniendo resultados del $90 \%$ en la extracción de los cloruros y la reducción simultanea de los óxidos de hierro. Si el artefacto está totalmente corroído, la temperatura debe superar los $500^{\circ} \mathrm{C}$. Esta técnica tiene como inconvenientes, la dificultad de manipular un gas altamente inflamable como el hidrógeno, y el elevado coste de las instalaciones.

\section{Limpieza Galvánica o Polarización indirecta (6)}

Este sistema tiene utilidad para el tratamiento simultáneo de un gran número de piezas de pequeño tamaño, que estén ligeramente corroídas. Consiste en colocar el objeto metálico que se va a tratar en contacto con una lámina de un metal más reductor que él, (zinc o aluminio), sumergido en un baño de un electrólito con $\mathrm{pH}$ básico renovado periódicamente, en el proceso el hidrógeno que evoluciona de la superficie del metal que constituye la pieza, actúa como agente reductor.

\section{Extracción electrolítica (7)}

Se lleva a cabo, una electrólisis sobre la pieza que actúa como cátodo, sumergida en una disolución conductora de $\mathrm{pH}$ básico $(\mathrm{NaOH}$ o $\mathrm{CO} 3 \mathrm{HNa})$ rodeada por un ánodo, generalmente de aluminio. Los compuestos férricos se reducirán en la reacción catódica produciendo compuestos más densos, favoreciendo la difusión de los iones cloruro (Cl-) que migrarán hacia el ánodo (polo positivo) atraídos electrostáticamente Durante el tratamiento debe controlarse la concentración de cloruros en la disolución, renovándola periódicamente, la diferencia de potencial (- I. IV(SHE)) sobre la pieza para asegurar que se encuentra en una zona de pasividad para el hierro al pH del tratamiento y la densidad de corriente $\left(0.05 \mathrm{~A} / \mathrm{cm}^{2}\right)$ que permite la eliminación eficaz de los cloruros.

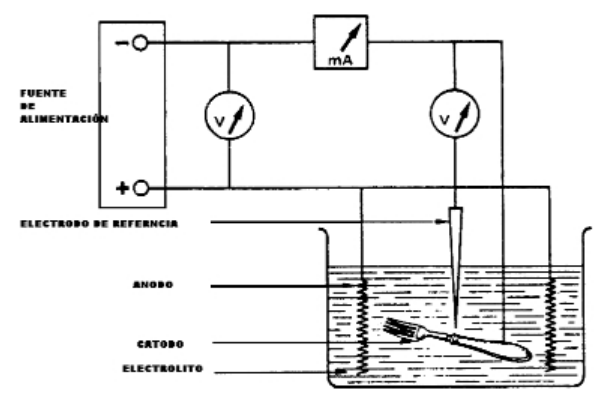

\section{Bibliografía}

( I) G.W.,ASHLEY;G.T.,BURSTEIN; Corrosion, 47, ( 99 I), ( I 2), 908-916.

(2) N.A: North; Studies in conservation, 27, (1982),75-83.

(3) H. KNIGHT; Corrosion of iron. Monograph, 1982, 53,50-55, London National Maritime Museum

(4) A. RINUY; F. SCHEWIEZER; Studies in conservation, 26, (I98I), 29-4I.
(5) N.A.NORTH, C. PEARSON; Studies in conservation, 22, (1977), |46-157.

(6) H.J., PLENDERHEIT; A:E.A. ,WERNER; The Conservation of Antiquities and Works of Art. Oxford University Press,London.

(7) R. BERTHOLON, N. LACOUDRE, J. MONTLUÇON, C. VOLFOVSKY; VAL 008/86.

Glosario de términos científicos

\begin{tabular}{|c|c|c|c|}
\hline ALCALINA & Referido a pH básico, pH>7 & \multirow[t]{2}{*}{ ELECTRÓLISIS } & \multirow{2}{*}{$\begin{array}{l}\text { Reacción química que tiene lugar cuando una } \\
\text { corriente eléctrica es aplicada a una sustancia. }\end{array}$} \\
\hline ANÓDICO & Proceso que tiene relación con el ánodo. & & \\
\hline ÁNODO & Electrodo donde tiene lugar la oxidación. & HIGROSCÓPICO & $\begin{array}{l}\text { Sustancia que espontáneamente absorbe agua } \\
\text { del ambiente. }\end{array}$ \\
\hline CATÓDICO & Proceso que tiene relación con el cátodo. & MONOCAPA & Capa de grosor molecular. \\
\hline CÁTODO & Electrodo donde tiene lugar la reducción. & \multirow[t]{2}{*}{ OXIDACIÓN } & \multirow{2}{*}{$\begin{array}{l}\text { Reacción química donde el estado de oxidación } \\
\text { de un elemento se hace más positivo. } \\
\mathrm{Fe}^{2}+\mathbb{E F e}^{3+}\end{array}$} \\
\hline CLORADAS & $\begin{array}{l}\text { Especies químicas que tienen cloro en su } \\
\text { composición. }\end{array}$ & & \\
\hline CONCRECIÓN & $\begin{array}{l}\text { Mezcla heterogénea de material calcáreo, de } \\
\text { origen marino. }\end{array}$ & \multirow[t]{2}{*}{$\mathrm{PH}$} & \multirow{2}{*}{$\begin{array}{l}\text { Método para expresar la acidez }(\mathrm{pH}<7) \circ \\
\text { basicidad }(\mathrm{pH}>7) \text { de una sustancia en una escala } \\
\text { de I a } \mid 4 \text {. Es el logaritmo negativo de la } \\
\text { concentración de hidrógeno }\left(\mathrm{pH}=-\log \left|\mathrm{H}^{+}\right|\right) \text {. }\end{array}$} \\
\hline CORROSIÓN & $\begin{array}{l}\text { Proceso por el cual un metal se oxida } \\
\text { paulatinamente. }\end{array}$ & & \\
\hline \multirow{2}{*}{$\begin{array}{l}\text { DENS. } \\
\text { CORRIENTE }\end{array}$} & Amperios por unidad de área introducidos en la & PPM & $\begin{array}{l}\text { partes por millón equivale a miligramos de soluto } \\
\text { por litro de disolución. }\end{array}$ \\
\hline & del circuito. & \multirow[t]{2}{*}{ REDUCCIÓN } & \multirow{2}{*}{$\begin{array}{l}\text { Reacción química donde el estado de oxidación } \\
\text { de un elemento se hace más negativo } \mathrm{Cl}_{2} \rightarrow 2 \mathrm{Cl} \text {. }\end{array}$} \\
\hline \multirow{2}{*}{$\begin{array}{l}\text { DIF. } \\
\text { POTENCIAL }\end{array}$} & Diferencia de potencial entre el cátodo y un & & \\
\hline & $\begin{array}{l}\text { electrodo tomado como referencia. } \\
\text { Generalmente } \mathrm{Ag} / \mathrm{ClAg} / \mathrm{CINa} /\end{array}$ & \multirow[t]{2}{*}{ SHE } & \multirow{2}{*}{$\begin{array}{l}\text { Electrodo estándar de hidrógeno, su potencial se } \\
\text { toma como referencia para elaborar la serie } \\
\text { electroquímica de potenciales normales de } \\
\text { reducción. }\end{array}$} \\
\hline \multirow[t]{2}{*}{ DIFUSIÓN } & $\begin{array}{l}\text { Proceso de expansión espontaneo para ocupar } \\
\text { uniformemente un espacio. Las diferencias de }\end{array}$ & & \\
\hline & $\begin{array}{l}\text { concentración en una disolución se igualan por } \\
\text { difusión. }\end{array}$ & $\begin{array}{l}\text { ZONA DE } \\
\text { PASIVIDAD }\end{array}$ & $\begin{array}{l}\text { En estas condiciones se produce la } \\
\text { transformación de una superficie aquejada de } \\
\text { corrosión en una superficie estable. }\end{array}$ \\
\hline
\end{tabular}




\section{PH Boletín 35}

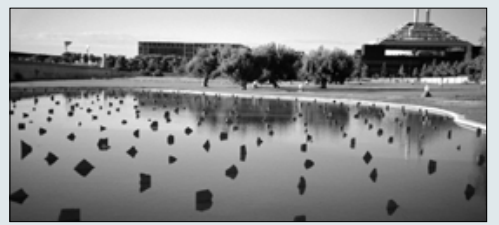

En Andalucía, una comunidad autónoma joven, con larga experiencia y desarrollo en potenciar retos en el Patrimonio Histórico, es relevante, por lo que tiene de inusual, que el IAPH se preocupe no sólo del Patrimonio, con mayúsculas, sino de los patrimonios, de aquellas manifestaciones creativas que quieren ser y tienen vocación de referentes presentes/futuros de la sociedad que los genera.

El arte contemporáneo, que en el comienzo de siglo superó al concepto de lo moderno, es una realidad incontestable adherida a muchas expresiones artísticas. La vecindad en el tiempo de su génesis (algo más de un siglo), su movilidad y la constante repercusión social, nos impiden entender su fragilidad, así como la dificultad para conservarlo y que se convierta en un elemento de trasferencia, al igual que otros elementos del Patrimonio.

Establecer los mecanismos para su interpretación, conocimiento y disfrute es la intención de esta selección de artículos, con la que esperamos se inicie un nuevo camino temático en esta publicación.

José Carlos Roldán Saborido Coordinador del Dossier 
Argumentando las bases de una colección. Pasado, presente y futuro de los fondos del Centro Andaluz de Arte Contemporáneo

La colección de un autor y su conservación (el caso Dalí)

Georgina Berini Aytés.

Aproximación al estudio de las obras de arte contemporáneo

Emilio Ruiz de Arcaute

Conservación de obras de arte contemporáneo sobre papel: tres ejemplos de intervención

José Cortés Arjona

La conservación del arte contemporáneo

Pilar Sedano

La difusión de la obra contemporánea como factor de riesgo.

Movilidad y Conservación

José Carlos Roldán

Documentar la obra de arte. Reflexiones desde las bibliotecas de arte contemporáneo

Eduardo Camacho Rueda

\section{EducArt $\exists$}

Manuel García Rodríguez.

[Entrevista] Guillermo Pérez Villalta

Carlos Núñez Guerrero 